\title{
MULHER, AMOR E DESEJO SEGUNDO A LITERATURA AMOROSA DO ALTO IMPÉRIO
}

\author{
Lourdes M. Gazarini Conde Feitosa \\ Universidade Estadual Paulista
}

Resumo: Este ensaio faz uma análise da concep̧̧ão de feminilidade presente no Alto Império Romano, a partir de obras da literatura amorosa do período, em particular poesias de catulo e os amores e a arte de amar de Ovídio. Através da apresentação do apdrão de beleza e do conceito ético de comportamento, apreende-se no discurso veiculado, a idealização da imagem feminina, segundo os valores aristocráticos, grupo social ao qual pertencem os autores.

Palavras-chave: mulher, feminilidade, sexualidade.

Este estudo como preocupação a análise da concepção de fiminilidade presente na sociedade romana do Alto Império, período compreendido, aproximadamente entre os anos 27 a. C. e $160 \mathrm{~d}$. C.

Como infelizmente não temos muitos registros escritos pelas próprias mulheres, principalmente obras publicadas ${ }^{1}$, optamos, como fonte para tal estudo, por obras da literatura amorosa do Aoto Império, toda ela escrita por homens pertencentes à aristocracia romana. Assim, destacamos que as concepções apresentadas representam a reconstrução do conceito de feminilidade e so papel que as mulheres deveriam ocupar no seio da sociedade, segundo a ótica de homens pertencentes à classe rica detentora do poder ${ }^{2}$.

Para isto, serão utilizadas as obras literárias Poesias de Catulo e Os Amores, e A Arte de Amar de Ovídio.

\section{Catulo}

Em sua obra Poesias, Catulo identifica uma bela mulher pela estatura alta $(86,2,115)$; loira cabeleira $(64,63,72)$; olhos negros $(43,2,36)$; nariz pequeno $(43,1,36)$; língua elegante $(43,3,36)$; dedos compridos $(43,2,36)$; seios rosados $(64,64,72)$; braços lisos $(64,332,85)$ e membros níveos $(64,364,87)$.

Juntamente com a beleza física, 0 autor caracteriza os comportamentos valorizados nas mulheres, de acordo com o lugar ocupado por elas na sociedade.

1. Escavaçōes arqueológicas têm descoberto importantes registros deixados pelas próprias mulheres. Cf. Funari, P. P. A., 1989, p.52 e Birley, R., 1990, p. 15.

2. 0 próprio Catulo faz referência às suas terras localizadas no limite dos territórios de Tibur e de Sabina (Catulo, 1993, p.37. Ovídio, filho de familia patrícia, rico, participou da tribuna Judiciária e de cargos políticos (Ovídio, Introdução de José Pérez, s.d, p.15). 
A moça que se prepara para contrair laços matrimoniais precisa, de antemão, ter boa moral "...não pode ter qualquer intimidade que a boa fama aprove..." $(51,611-62,51)$. Ter boa fama significa comportar-se de maneira recatada e pura, garantindo o bom conceito maoral "a virgem, enquanto permanece pura é querida dos seus; mas quando seu corpo poluído perdeu a casta flor, já não é agradável aos rapazes e querida das raparigas" $(62,43-47,63)$. A boa virgem casase e é levada ao noivo pela dextra paterna "... a quem te levou o próprio pai" $(62,59$, 63 ); isso significa que não se trata de qualquer virgem, mas daquela que tem um berço familiar. A decisão pelo casamento é fruto de um acordo feito a nivel familiar, firmado em um contrato ante-nupcial "...os noivados prometidos pelos pais e pelas mães" $(62,27-28,61)$.

Na situação de casada, a mulher deve incorporar um conjunto de normas e comportamentos definidos socialmente; como uma boa esposa, deve respeitar e obedecer ao seu marido como o faz com os seus pais "... não lutes com um tal esposo, 6 virgem, não é justo lutar com aquele a quem levou o próprio pai com a mãe, e a eles é necessário obedecer" $(62,58-60,63)$.

Outro papel importante da esposa é a procriação. É através dela que sairão os descendentes responsáveis pela continuidade de sua familia: "Sem ti nenhuma casa pode dar filhos nem apoiar-se o pai na sua prole..." $(51,666-68,51)$.

A esposa virtuosa deve ser fisl ao seu marido ...viver contente com um só homem é para a esposa a maior de todas as glórias $(66,83,95)$. A castidade da esposa é socialmente caracterizada como uma virtude, contudo é um ato que não depende apenas da esposa, mas também do esposo. Para isso, é necessário um cuidado especial do marido na guarda de sua esposa "Esse homem... é casado com uma rapariga na flor da idade - e uma rapariga mais mimosa que o cabritinho novo deve ser guardada com mais cuidado que as uvas mais negras" $(7,13-16,18)$. 0 fato do homem cuidar e guardar a mulher como meio de assegurar a sua fidelidade não a caracteriza como sexualmente perversa; isso significa que a mulher, tal qual o cabritinho, é inocente e infantil e não tem discernimento para tomar decisões corretas, mesmo tendo recebido uma boa educação.

As várias enumerações feitas pelo autor como vigilância, contrato antenupcial, virgindade e fidelidade, idealizadas para a mulher destinada à relação legítima, leva-nos a crer que se trata de um conjunto de valores e comportamentos inseridos na ética social valorizados pela aristocracia, preocupada em fazer do casamento um acordo econômico, estabelecendo ligitamente seus herdeiros e garantindo o seu poderio político; interpretação semelhante é feita por Veyne (Veyne, 1990, p. 47) ao afirmar que as pessoas se casavam para esposar um dote e para ter rebentos legítimos que recolheriam a sucessão e perpetuariam o corpo cívico, o núcleo dos cidadãos.

Em contraposição à relação convencional considerada legítima pelo senso aristocrático, Catulo classifica o amor futrivo, representado por seu amor à Lésbia, mulher casada, da qual obtem futivos prazeres roubados dos braços do marido: "Ela não veio trazida, pela dextra paterna, para a minha casa fragrante de perfumes assírios, mas deu-me, uma admirável noite, furtivos prazeres roubados dos braços do marido" (68b, 101-105, 106).

Diferente do casamento, onde a fidelidade feminina está relacionada ao seu vom caráter, nada de concreto pode-se esperar da amante; nenhuma lei estabelece o comportamento a ser mantido entre eles: "Diz a mulher que amo que 
não se ligaria a nimguém senão a mim, ainda que a requestasse o próprio Júpiter. $E$ verdade que o diz: mas o que uma mulher diz ao cubiçoso amante deve-se escrever no vento e na rápida água" $(70,11-14,107)$.

Embora frágil, 0 autor elucida um acordo firmado entre o casal, no qual 0 homem procura acueditar na fidelidade da amante, mesmo sabendo que o próprio relacionamento mantido entre eles é fruto de um ato inffiel e, por isso, aceita, com ouca flexibilidade a infidelidade da amante: "Ainda que ela não se contente só com Catudo, suportarei as raras e escondidas infidelidades de minha senhora, para que nāo se torne, como os tolos, muito incômodo" (68b, 95-97, 105).

0 seu amor pela amante é nobre ${ }^{3}$ : "Adorei-te, não como vulgarmente se adora uma amante, mas como um pai adora os filhos e os genros" $(72,1-4,108)$.

Embora recebendo todo este amor, Lésbia coloca-o em questão diante de suas constantes infidelidades. Isto 0 faz rever a sua apreciação sobre a amnte: "agora sei quem és...desprezlvel e odinária" $(72,5-6,108)$. "Eu já não pretendo que ela corresponda ao seu amor, ou, o que é impossivel, que queira ser honesta..." (76, 23-24, 111). Percebemos que enquanto Catulo procura acreditar no amor e na fidelidade da amante, 0 seu julgamento sobre ela é condescendente e os seus conceitos alcançam padrōes nobres como integridade e honestidade; porém, ao sentir-se constantemente traído, luta para desvencilhar-se deste sentimento e julga a ex-amante como ordinária, despresivel e desonesta, características de uma mulher leviana, ou seja, que não respeita acordo slugum.

0 ponto comum existente entre a relação lefítima e a furtiva é o pacto de fidelidade, sinal de compromisso, estabelecido entre o casal, dierente da relação de um homem com uma prostituta. Nesta relação não se pode estabelecer pactos, pois a prostituta "com suas ofertas inúteis e desonestas" $(66,84-85,95)$ é "aquela que vedes andar com descaramento e que rfinsipidamente" $(42,7-8,35)$. A prostituta é um ser sórdido que busca apenas o seu interesse pessoal e, principalmente, que se vende.

Concluímos que 0 ideal de beleza feminina apresentada por Catudo é aquele em que a mulher bem tratada, com longos cabelos cuidados e pele alva que não se expõe ao sol para trabalhos, o julgamento que se faz de seu comportamento valoriza a sua indole, a virgindade, a fidelidade e a obediência, atributos assegurados pelos cuidados dos homens para com elas.

\section{OvíD10}

Ovido escreveu obras expressivas sobre as relações amorosas, fato que nos ffez optar por duas delas: Os Amores e A Arte De Amar. As obras de Ovídio Serão indicadas no texto, respectivamente, com os prefixos (A) e (AA).

Iniciaremos com 0 conceitode beleza feminina abordado pelo autor: cabelos longos $(A, 3,3,273)$, fino e loiro $(A, 3,10,401)$, rosto níveo $(A A, 1,3,259)$, niveos braços e seios (A, 2, 16, 343), nivea mão (A, 2, 11, 330), talhe alto e perfeito

3. Em seu artigo sobre prática matrimonial e representaçáo filosófica, M. Benabou (Benabou, 1987, p.1261) analisa a descriçăo deste amor de Catulo por Lésbia, no qual o autor sonha sentir na relação imprevisivel que $\mathbf{e}$ a sua união à Lésbia, as qualidades positivas ligadas ao status matrimonial, como a segurança da estabilidade garantida por um verdadeiro pacto. Sonha 0 autor, ora com a fidelidade, ora com a eternidade, singulares da cúpula legítima. 
$(A, 2,4,303)$, cintura gentil, coxa refeita, juvenil $(A, 1,5,246)$, roliça $(A, 3,7,387)$, curvas mimosas $(A, 1,4,242)$.

A mulher deve possuir elegância discreta ( $A A, 3,98)$, saber ler poesias (AA, 3, 105), fazer voz melodiosa (AA, 3, 104), tocar e dançar (AA, 3, 105 e 108), praticar mil jogos (AA, 3, 108), dominar-se e ser alegre (AA, 3, 114).

"A beleza é um dom dos deuses; quantas porém se podem orgulhar de sua beleza? A maioria de nós não recebeu este dom" (AA, 3, 97). É desejável que a mulher se aproxime tanto quanto possivel, do ideal de beleza descrito; para isto, todo esforço é válido: os cabelos brancos devem ser tingidos e cuidados (AA, 3, 103), deve-se caminhar como convém à mulher, pois andar: "atrai ou faz fugir ... os homens desconhecidos" (AA, 3, 104). Nos festins a mulher deve pegar os alimentos com a ponta dos dedos, não sujar o rosto com as mãos não enxutas e não comer nem beber muito (AA, 3, 122-123). 0 terrivel bodum não deve morar em suas axilas, as pernas não devem ficar cobertas de pêlos ásperos, os dentes escuros pela preguiça e o rosto deve ser lavado pela manhã (AA, 3,100$)$.

Segundo 0 parecer de Ovídio, a simplicidade, 0 pejo das faces, a modéstia, a castidade e a virtude de caráter $(A, 1,3,237)$, são qualidades femininas que sempre encantam o seu par; estes atribuitos simbolizam a mulher de boa índole e de moral valorizada.

E a elas que 0 autor dirige seus ensinamentos? Preocupa-se ele em frisar que não: "não falarei sobrea maneira de iludir a vigilância de um amrido sagaz ou de um gardião atento. Que a mulher casada tema ao marido; que sua vigilância seja bem assegurada: assim convém, assim mandam as leis e o decoro. Tu, também submetida a tal viglância, tu libertada a pouco, que farás? Para enganares, vem ao meu culto." (AA, 3, 117).

Ovídio quer levar o leitor a crer que o alvo dos sues ensinamentos é a mulher liberta, mulher de costumes livres; chamada cortesã, cujo relacionamento livre parece ser admetido pela moral.

Entretanto, 0 autor isenta deste tipo de relacionamento que envolve, além do sexo, amor e carinho, a escrava e a prostituta. "Nunca o céu permitisse aos meus afetos entregar-se tão baixo; que espirito elevado suportaria os mimos, os favores, de concição tão vil?" (A, 2, 7, 316) ou "Desprezo ainda maior, maior horror merece a que faz de seu leiro um meio d'intersse, e prostitui seus dons, e vinde o seu prazer" (A, 1, 10, 268). Mas se confiássemos apenas nestas palavras de Ovídio, como entenderíamos os diversos ensinamentos por ele escritos a fim de driblar uma boa vigilância, seja ela do guardião, do pai ou do marido? (AA, 3, 117-119). Certamente um relacionamento moralmente aceito como era com as cortesãs, não exigiria mais cuidados. "0 prazer é menor quando não é rodeado de perigo" (AA, 3, 117). Acredito que Ovídio refira-se a estas mulheres, retratadas principalmente nos conselhos de etiqueta social colodados por ele, mas não esclusivamente a elas; ele inclui no público de seus ensinamentos também a mulher da alta sociedade, cuja moral exige pudor, castidade e vigilância. Neste meio, supostamente composto por mulheres honestas, educadas e guardadas para 0 casamento e para a fidelidade, Ovídio aborda as peripécias dos amantes para burlar as vigilâncias: "Através de espertos guardas, de mil vigias romper. Eis 0 dever de um soldado, dum pobre amante dever". $(A<1,9,264)$ e, "Acrísio, em pessoa vigiou sua filhazelozamente; els porém teve sua aventura que o tornou avô" (AA, 3, 118). Fica evidente, portanto, a 
necessidade de burlar o zelo da vigilância e que as palavras do autor não são dirigidas apenas às mulheres autorizadas "pelo pudor, pelas leis e por seu estado".

Podemos considerar alguns traços da figura feminina, segundo 0 exposto por Ovídio: primeiro, a certeza masculina de que toda mulher é conquistável, convencido de que a boa conquista "depende apenas da maneira de colocar as armadilhas" (AA, 1, 32); segundo, a afirmação de que 0 alto-domínio não faz parte da personalidade feminina; as mulheres se deixam convencer pelos homens que as solicitam: "Enquanto Menelau estava ausente, Helena, para não ficar só, encontrou, à noite, um confortador abrigo nos braços do amante. Que tolice foi essa Menelau? Partiste sozinho, deixando, sob mesmo teto, o teu hospede e tua esposa. Helena não pecou, seu amante não delingüiu... eu absolvo Helena, ela se aproveitou de um marido benevolente" (AA, 2, 71-72). A fidelidade feminina é uma atitude valorizada, mas não se confia na existência de uma natureza fiel e sim na importância da constante viglância: "Marido... é necessario guardar melhor a esposa..." (A, 3, 19, 353), ou "Que a mulher casada tema o marido; que sua vigilância seja bem assegurada" (AA, 3, 117).

Conclứmos que a concepção de feminilidade analisada im Ovídio, idealiza os aspectos físicos e comportamentais, os bons tratos e a educação da mulher da alta sociedade; quanto ao caráter, a falta de auto-domínio e confiabilidade são considerados como aspectos inerentes ao sexo feminino.

\section{Conclusão}

Analisando conjuntamente as abordagens de Catulo e Ovídio, percebemos semelhanças na idealização que fazem da beleza feminina, realçando em seus aspectos físicos as características de uma mulher branca, bem nutrida, com faces coradas e estatura airosa, longos cabelos e com disponibilidade de tempo para tomar os cuidados gerais com o seu corpo; nos aspectos comportamentais, é valorizada a educação, a leitura, o recato e a elegância, entre outros; estes exemplos mostra-nos que o ideal de feminilidade apresentado tem como modelo a mulher da alta sociedade, cuja posição social lhe garante 0 acesso a tais requisitos.

Segundo o parecer dos autores, a personalidade feminina é marcada pela ausência de discernimento e auto-controle, propiciando a mulher 0 prazer desonesto. Com isso, faz-se necessário o direcionamento da conduta feminina pelo homem, que é racional e conhecedor dos melhores caminhos. Estes argumentos, entretanto, nos leva a crer numa submissão não passiva da mulher, em relação a imagem feminina idealizada pelo discurso veiculado; dal, a necessidade do controle permanente.

Agradecimento: Expresso o meu agradecimento ao professor Pedro Paulo A. Funari pelo fornecimento de textos, apoio e estímulo no estudo da Antiguidade Clássica. 
Abstract: This essay analises the conception of femininity present in the High Roman Empire, from works of afectinate litetature of the period, in particular, Poems of Catulo and The Art of Loving of Oviidio. Through the presentation of beauty standard and the ethic concept pf behaviour, it apprehends itself, in the introduced speech to the idealization of a female image according to aristocratical values, the social group which the authors belong to.

Bibliografia

BENABOU, M. Pratique matrimonials et représentation philosophique: le crépuscule des stratégies. Annates, Economies, Sociétés, Civilizations. v.42, n.6, p.1255-1266, 1987 :

BIRLEY, R. The Roman documents from Vindolanda. Vindolanda, 1990.

CATUlo. Poesias. Tradução de Agostino da Silva. Cimbra: Imprensa da Universidade, 1933.

FUNARI, P. P. A. Cultura popular na Antiguidade Clássica. São Paulo, Contexto, 1989.

ovíDıo. A Arte De Amar. Tradução de David Jardim Junior. Rio de Janeiro: Tecnoprint S.A., s.d.

. Os Amores. Tradução de Antonio Feliciano de Castilho. 2.a ed. São Paulo: Cultura, 1945.

VEYNE, P. 0 Império Romano. In: ARIES, F. e DUBY, G., org. História da vida privada. Do Império romano do ano mil. São Paulo: Cia das Letral, 1900. 